\title{
THE EFFECT OF ROOT REINFORCEMENT EXEMPLIFIED BY BLACK ALDER (ALNUS GLUTINOSA GAERTN.) AND BASKET WILLOW (SALIX VIMINALIS) ROOT SYSTEMS - CASE STUDY IN POLAND
}

\author{
ZYDROŃ, T. ${ }^{*}-$ SKÓRSKI, Ł. $^{2}$ \\ ${ }^{I}$ Faculty of Environmental Engineering and Land Surveying, University of Agriculture \\ in Kraków, Mickiewicza 24/28, PL-30-059 Kraków, Poland \\ (phone: +48-12-662-4161) \\ ${ }^{2} M G G P$ S.A. \\ Biecka 1, PL-38-300 Gorlice, Poland \\ (phone: +48-18-353-7805) \\ *Corresponding author \\ e-mail:t.zydron@ur.krakow.pl \\ (Received $19^{\text {th }}$ Jul 2017; accepted $24^{\text {th }}$ Nov 2017)
}

\begin{abstract}
This paper is focused on evaluation of the effect of roots of two species - black alder (Alnus glutinosa Gaerin.) and basket willow (Salix viminalis) on the increase in soil shear strength (root cohesion). The second aim of the paper was to compare the results of calculating root cohesion using the classical Wu/Waldron model and selected fiber bundle models, especially in the context of determining the influence of the criterion of distribution of stresses on calculation results. The research on the studied plant species was conducted on a seven-year plantation of energy crops located in Krakow, Poland, where the test area was modified by covering the natural site by anthropogenic soil. In order to determine the root cohesion site investigations, which included measurements of root area ratio, and laboratory tests, which included determination of root tensile strength, were conducted. The results of root cohesion calculation revealed that the studied species have relatively low values of this parameter. It was also shown that fiber bundle models yield lower values of root cohesion than the classic Wu-Waldron model. Among the fiber bundle models, the lowest values of the investigated parameter were obtained using the deformation model that takes into account the function of probability distribution of root tensile strength.

Keywords: root reinforcement, slope stability, fiber bundle models
\end{abstract}

\section{Introduction}

Research on the effect of plant root systems on slope stability is an issue that scientists have been investigating since the second half of the $20^{\text {th }}$ century. Results of these investigations show significant importance of roots in soil stabiliazation. The range of soil stabilization depends on the architecture and strength of the root system, and these features are determined by specific features of plants and by environmental conditions (Bischetti et al., 2007, 2009). These relations are the reason why knowledge concerning mechanical (strength-related) characteristics of root systems is relatively scarce and requires further research (Mattia et al., 2005; Bischetti et al., 2009), especially in terms of the effect of bioengineering techniques on slope stability. The main goal of the paper was to evaluate the effect of roots of two species - black alder (Alnus glutinosa Gaerin.) and basket willow (Salix viminalis) on the increase in soil shear strength. These species are used in reclamation of degraded lands (Jaworski, 1995; Stachowski, 2006), they are tolerant to high soil moisture, and even to periodical floodings, which makes them potentially useful for stabilization of 
riverbanks or for the improvement of slope stability in landslide-prone regions. We hypothesized that soil reinforcement of root system of both species will not be high because of their age, but there will be a significant difference between species.

In non-rooted soil shear strength can be described using classical Mohr-Coulomb theory $(E q .1)$ :

$$
\tau_{f}=\sigma \cdot \tan \phi^{\prime}+c^{\prime}
$$

where: $\tau_{\mathrm{f}}-$ shear strength of soil, $\sigma$ - normal stress, $\phi '-$ effective angle of internal friction, c' - effective cohesion.

In rooted soil its displacement mobilize tension development within roots, which provides increase of soil shear strength, described as an additional cohesion (Eq. 2):

$$
\tau_{f}=\sigma \cdot \tan \phi^{\prime}+c^{\prime}+c_{r}
$$

where: $\tau f, \sigma, \phi$ ', c', cr - the increase of cohesion due to presence of roots (or root cohesion; (Mattia et al., 2005; Bischetti et al., 2009).

Reinforcement of soil by presence of root, commonly called root cohesion (Bischetii et al., 2009), is determined by conducting direct field investigations (Mickovski and van Beek, 2009; Comino and Marengo, 2010; Rai and Shrivastva, 2012) and using calculation methods (Schmidt et al., 2001; Mattia et al., 2005; Burylo et al., 2011) or using back analysis (Sonenberg et al., 2010). Particularly useful is the second group of methods, which involves determination of the root area in the soil profile and determination of the root tensile strength or root pull-out resistance, followed by calculation of root cohesion. The advantage of this type of solution is a considerable reduction in the scope and costs of field work compared to in-situ tests and relatively low invasiveness of the method. The classical way of determining the effect of root systems on the increase in soil shear strength was proposed by Wu et al. (1979) and Waldron (1977). This model assumes that, during shearing, full mobilization of the tensile strength of all roots in the bundle takes place. As the results of direct investigations (Docker and Hubble, 2008; Pollen and Simon, 2005) indicate, using the $\mathrm{Wu}$ /Waldron model usually leads to overestimation of the influence of plant root systems on soil shear strength. Therefore, in recent years, the range of root cohesion has been determined using fiber bundle models (Pollen and Simon, 2005; Mao et al., 2012; Schwarz et al., 2012; 2013). These models assume irregular mobilization of maximum tensile strengths in individual parts of the root bundle, but these models differ in assumptions concerning the manner of distribution of root tensile strengths and root elasticity. That is why the second goal was to compare the results of calculating root cohesion using the classical $\mathrm{Wu} / \mathrm{Waldron}$ model and selected fiber bundle models, especially in the context of determining the influence of the criterion of distribution of stresses on calculation results. We expected that fiber bundle models will give different calculation results and it would be possible to indicate the model which provides the most conservative values of root cohesion. 


\section{Materials and methods}

\section{The research area}

The research on the studied plant species was conducted on a seven-year plantation of energy crops located at the premises of the Faculty of Production and Power Engineering of the University of Agriculture in Krakow, Poland (N 50 4'54, E 19 $52^{\prime} 2$ ). The research area was located in an area subjected to anthropogenic modification of its morphology. The modification consisted in bringing silty sand soil (0.5-0.6 m thick) consisting also industrial wastes (pieces of furnace slag, bricks, concrete) onto the plot surface. Natural soil also includes sandy silty soil which is characterized by dark-gray color and low porosity. During the research, presence of plants from the Equisetaceae family from was found in this soil, which (in relation to land morphology) indicates that before the modification the natural land had been waterlogged. Apart from the studied species, test area was also covered by herbaceous species. In case of black alder dominant species were ground elder (Aegopodium podagraria L.) and common nettle (Urtica dioica L.). In the vicinity of basket willow prevailed Canadian goldenrod (Solidago canadensis), but giant goldenrod (Solidago gigantea), ground elder (Aegopodium podagraria L.), cock's-foot (Dactylis glomerata L.), reed canary grass (Phalaris arundinacea L.) and Tanacetum boreale (Chrysanthemum vulgare L.) were also found.

\section{Field investigations}

Measurements of the root area ratio (Ar/A) were carried out using a vertical trench profile wall method (Böhm, 1979) for six plants from each species. Root area ratio was defined as the fraction of the soil cross sectional area occupied by roots per unit of the excavated area (Comino et al., 2010) and it was assumed that roots are circular in crosssection. Excavations were executed $(1.0 \mathrm{~m}$ wide and at least $0.80 \mathrm{~m} \mathrm{bgl})$ at a distance of approximately $0.5 \mathrm{~m}$ from the tree. The depth of excavation was dependent on the presence of roots, and when they occurred the excavations were done at least $0.1 \mathrm{~m}$ deeper than the deepest-occurring roots. The distance of excavation from the tree was established based on preliminary tests which showed that there are only single roots at $1.0 \mathrm{~m}$ from the tree. After cleaning the excavation wall surface, measurements of root diameters (at vertical spacing of $0.1 \mathrm{~m}$ ) were taken. The analysis omitted roots smaller than $1 \mathrm{~mm}$ and bigger than $10 \mathrm{~mm}$ in diameter. Fine roots are difficult to distinguish and determine, and coarse roots are so stiff that they do not cooperate with soil in accordance with the assumptions of basic calculation models (Bischettii et al., 2009). Roots of the tested species were distinguished from the others on the basis of color, smell and texture.

Field investigations of soils involved determining their volumetric density using the cutting ring method and determining the natural moisture content using the drying and weighing method (weight moisture) and using time domain reflectrometry (TDR) (volumetric moisture).

The analysis of the research results consisted in determining the significance of differences in the amount of roots and their relative area in distinguished layers of the profile between both plant species. Normality of data distribution was analyzed first (using the Shapiro-Wilk test), and then, due to lack of normality of distribution of the analyzed parameter, the U Mann-Withney test was used. 
For quantitative description of root distribution in the profile, the Gale and Grigal's equation $(1987 ; E q .3)$ was used:

$$
Y=1-B^{D}
$$

where: $\mathrm{Y}$ - cumulative number of roots in the soil profile, expressed as the percentage of roots, D - depth, B - the fitted coefficient.

\section{Laboratory tests}

The scope of the tests included determination of tensile strength of root samples of both plant species using a Hounsfield H50KS tensile testing machine. Before testing, the root samples were submerged in water for approximately 1 day in order to obtain their maximum possible saturation. The total length of the samples was approximately $20 \mathrm{~cm}$, and effective distance between machine jaws was $10 \mathrm{~cm}$. On the other hand, the tension speed was $10 \mathrm{~mm} \mathrm{~min}^{-1}$. The test was conducted until the sample broke or came out of the jaws. The diameter of the sample was measured at the breaking point, at the same time noting the way it was destroyed. Then, taking into account root diameter and the value of tensile force, root tensile strength was calculated. The statistical analysis of the research results consisted in establishing the relationship between tensile force and root diameter and the relationship between tensile strength and root diameter. This analysis was conducted in Microsoft Excel, using the least squares method, and only the samples broken between machine jaws were used for the analysis.

On the other hand, the significance of differences in tensile strength between the studied plant species was analyzed in Statistica using the analysis of covariance (ANCOVA). In this analysis, root diameter was the covariate, and the value of tensile force was the dependent variable. Before commencing the analysis, values of both parameters had been logarithmized, followed by verification of normality of their distribution using the Shapiro-Wilk test for significance level 0.05.

\section{Calculations of root cohesion}

The value of root cohesion $\left(\mathrm{c}_{\mathrm{r}}\right)$ was determined based on the measurement results of the root area ratio and determination results of root tensile strength, using the classic Wu-Waldron model (Waldron, 1977; Wu et al., 1979) and five fiber bundle models. In the first model (W-W), root cohesion was calculated according to the following equation:

$$
c_{R}=k^{\prime} \cdot k^{\prime \prime} \cdot \sum_{i=1}^{N} T_{R i} \cdot\left(\frac{A_{r i}}{A}\right)
$$

where:

k' - root orientation factor, assumed usually within the range 1.0-1.3; the calculations assumed $\mathrm{k}$ ' $=1.2, \mathrm{k}$ " - correction factor, proposed by Preti (2006); k" $=1.0$ was assumed, $\mathrm{T}_{\mathrm{Ri}}$ - root tensile strength, $\mathrm{A}_{\mathrm{ri}}$ - root area ratio in the soil, $\mathrm{A}$ - area of the studied section.

The disadvantage of Wu-Waldron model is the assumption that soil shearing is accompanied by mobilization of full tensile strength of all roots in the system. Such an assumption is the reason why the effect of root systems on root cohesion is overestimated (e.g. Pollen and Simon, 2005). That is why Preti (2006) suggested that 
values of root cohesion calculated using Equation 4 be corrected by introducing the k" factor to the original formula of $\mathrm{Wu}$-Waldron model.

The fiber bundle model (FBM) assumes that breaking of roots during soil shearing takes place successively. Initially, soil load is distributed evenly to all roots until breaking of the weakest root. As a result, tensile force is transmitted onto a system with the smallest number of roots (n-1), which means that there is an increase in the force transmitted to a single root. There are several criteria describing the mechanism of destruction (breaking) of the root system. Five calculation models were used in this paper. One group includes the so-called static models, which take into account mainly information on dimensions of roots and their tensile strength. These models assume that the amount of tensile strength can be distributed to roots proportionally to their section area (FBM1), to their diameter (FBM2) or their number in a bundle (FBM3). In the first case (FBM1), it is assumed that each root is subjected to the same tensile stress, and the value of root cohesion is calculated from the following dependence (Eq. 5; Mao et al., 2012):

$$
c_{R}=k^{\prime} \cdot\left(T_{r j} \cdot \sum_{n=1}^{j} \frac{A_{r n}}{A}\right)
$$

where:

k' - assumed as in formula (4), $\mathrm{T}_{\mathrm{rj}}$ - "j" root tensile strength, $\mathrm{A}_{\mathrm{rn}}$ - cross-section area of intact roots in a bundle, A - as in Equation 4.

In the second case (FBM2), the value of force transmitted to roots is proportional to root diameter, according to the proposition made by Pollen and Simon (2005), and the value of root cohesion is determined from the following dependence (Eq. 6; Mao et al., 2012):

$$
c_{R}=k^{\prime} \cdot\left(T_{r j} \cdot \frac{A_{r j}}{A} \cdot \frac{\sum_{n=1}^{j} d_{n}}{d_{j}}\right)
$$

where: k' - assumed as in Equation 4, $\mathrm{T}_{\mathrm{rj}}$ - tensile strength of a root with diameter $\mathrm{d}_{\mathrm{j}}$, $A_{r j}$ - cross-section area of a root with diameter $d_{j}, d_{n}$ - root diameter, $d_{j}$ - diameter of the root with the lowest tensile strength in the bundle.

On the other hand, according to the third criterion (FBM3), tensile force transmitted by individual roots is identical, and its value is proportional to the number of roots. The calculations were made using the following formula (Eq. 7; Mao et al., 2012):

$$
c_{R}=k^{\prime} \cdot\left(T_{R j} \cdot \frac{A_{R j}}{A} \cdot j\right)
$$

where: $k^{\prime}$ - as above, $T_{R j}$ - tensile strength of the weakest root in the bundle, $A_{R j}$ - root area in soil, $\mathrm{j}$ - number of unbroken roots in the system, A - as above.

The drawback of the above-described models is the assumption of identical elasticity of all roots in the bundle. Schwarz et al. (2012) proposed a modification to fiber bundle model - Root bundle model (RBM1). The modification consisted in the assumption that each root has its own distinct geometric and strength-related properties. To calculate the 
properties of individual roots, the authors of this model proposed the following equations (Eqs. 8, 9 and 10):

$$
\begin{gathered}
L(d)=L_{0} \cdot\left(\frac{d}{d_{0}}\right)^{\gamma} \\
E(d)=E_{0} \cdot\left(\frac{d}{d_{0}}\right)^{\beta} \cdot r \\
F_{\max }(d)=F_{0} \cdot\left(\frac{d}{d_{0}}\right)^{\xi}
\end{gathered}
$$

where: L - length of a root with diameter "d", $L_{0}$ - empirical characteristic length of a root with diameter $\mathrm{d}_{0}, \gamma, \xi, \beta$ - exponent, $\mathrm{d}_{0}$ - diameter of a characteristic root, usually assumed as $\mathrm{d}_{0}=1 \mathrm{~mm}$ (in order to obtain dimensionless term of Equations 6-8 occurring in parenthesis, E(d) - Young's module for a root with diameter "d", $E_{0}$ - empirical characteristic Young's module for a root with diameter $\mathrm{d}_{0}, \mathrm{r}-$ dimensionless factor introduced in order to take into account the effect of root tortuosity on its behavior under tension (assumed as $\mathrm{r}=0.4$ ), $\mathrm{F}_{\max }$ - maximum tensile force, $\mathrm{F}_{0}$ - empirical characteristic tensile force of a root with diameter $\mathrm{d}_{0}$.

For the purpose of the analysis, the $\mathrm{L}_{0}, \gamma$ and $\mathrm{r}$ values were assumed based on data provided by Schwarz et al. (2012). On the other hand, Young's module and $\beta$ values were estimated based on test results on tensile strength, being aware, however, of the fact that these were approximate values with no significant effect on the results of calculations of the value of the force distributed by roots.

By integrating the above-mentioned equations one can obtain relationships which make it possible to determine the value of tensile strength occurring in the investigated range of deformation for individual roots in the bundle. As a result, it is possible to obtain a value of tensile strength transmitted by the root system which, after comparing it to the area of the investigated section, can be calculated into the value root cohesion. Schwarz et al. (2013) established that test results on tensile strength and pull-out strength are characterized by substantial variability in the studied property. That is why they proposed to take into account, when calculating the value of tensile strength transmitted by roots, the probability of root breaking described by means of the Weibull survival function, according to the following dependence (Eq. 11 and 12; RBM2):

$$
F_{t o t}(\Delta x)=\sum_{i=1}^{N} F(d, \Delta x) \cdot S\left(\Delta x_{i}^{*}\right)
$$

where: $\mathrm{S}(\Delta \mathrm{x} * \mathrm{i})$ - two-parameter Weibull survival function:

$$
S\left(\Delta x^{*}\right)=\exp \left[-\left(\frac{\Delta x^{*}}{\lambda}\right)^{\omega}\right]
$$


where: $\omega$ - indicator of the shape of Weibull function, $\lambda-$ scale parameter, $\Delta \mathrm{x}^{*}-$ normalized deformations of a root with diameter "d", calculated as the ratio of the value of deformation (obtained from tests) at the moment of breaking to theoretical value of this parameter, $\mathrm{F}(\mathrm{d}, \Delta \mathrm{x})$ - value of tensile force of a root with diameter " $\mathrm{d}$ " at deformation $\Delta \mathrm{x}$.

A detailed procedure for determining the value of survival function parameters is described in the paper by Schwarz et al. (2013). To determine the values of Weibull function parameters, results of tests on the root samples tension were used.

Table 1 summarizes similarities and differences of the models described above.

Table 1. Properties of theoretical models used for calculation of root cohesion

\begin{tabular}{|c|c|c|c|c|c|c|}
\hline \multirow{2}{*}{ Properties } & \multicolumn{6}{|c|}{ Model } \\
\hline & W-W & FBM1 & FBM2 & FBM3 & RBM1 & RBM2 \\
\hline $\begin{array}{c}\text { Tensile force } \\
\text { distribution } \\
\text { within bundle }\end{array}$ & $\begin{array}{c}\text { Not } \\
\text { included }\end{array}$ & $\begin{array}{c}\text { Due to root } \\
\text { cross } \\
\text { section area }\end{array}$ & $\begin{array}{l}\text { Due to } \\
\text { root } \\
\text { diameter }\end{array}$ & \begin{tabular}{|c|} 
Due to \\
number of \\
roots
\end{tabular} & $\begin{array}{l}\text { Due to root cross } \\
\text { section area and } \\
\text { root's deformation }\end{array}$ & $\begin{array}{l}\text { Due to root cross } \\
\text { section area and } \\
\text { root's deformation }\end{array}$ \\
\hline $\begin{array}{c}\text { Deformation } \\
\text { analysis }\end{array}$ & $\begin{array}{c}\text { Not } \\
\text { included }\end{array}$ & $\begin{array}{c}\text { Not } \\
\text { included }\end{array}$ & $\begin{array}{c}\text { Not } \\
\text { included }\end{array}$ & $\begin{array}{c}\text { Not } \\
\text { included }\end{array}$ & Included & Included \\
\hline $\begin{array}{c}\text { Order of root } \\
\text { breakage }\end{array}$ & $\begin{array}{c}\text { Not } \\
\text { included }\end{array}$ & $\begin{array}{l}\text { Acc. to } \\
\text { tensile } \\
\text { strength }\end{array}$ & $\begin{array}{l}\text { Acc. to } \\
\text { tensile } \\
\text { force }\end{array}$ & $\begin{array}{l}\text { Acc. to } \\
\text { tensile } \\
\text { force }\end{array}$ & $\begin{array}{l}\text { Acc. to relative } \\
\text { deformation }\end{array}$ & $\begin{array}{c}\text { Acc. to relative } \\
\text { deformation }\end{array}$ \\
\hline $\begin{array}{c}\text { Maximum tensile } \\
\text { strength of a } \\
\text { single root }\end{array}$ & Constant & Constant & Constant & Constant & Constant & $\begin{array}{l}\text { Described by } \\
\text { Weibull survival } \\
\text { function }\end{array}$ \\
\hline $\begin{array}{c}\text { Number of model } \\
\text { parameters }\end{array}$ & 2 & 2 & 2 & 2 & 4 & 6 \\
\hline $\begin{array}{l}\text { Difficulty of } \\
\text { method }\end{array}$ & Low & Medium & Medium & Medium & High & High \\
\hline
\end{tabular}

To determine the significance of differences in values of root cohesion obtained from different methods, averaged values of this parameter in the entire profile were calculated, then ANOVA test was used at a significance level of 0.05 .

\section{Results}

\section{Root area ratio (Ar/A)}

The results of site measurements revealed that total number of roots in the profile in individual test excavations was not very high and ranged from 35 to 92 for black alder and from 34 to 40 in the case of basket willow. In Table 2 number of roots converted into pieces per square meter is presented. The analysis of root distribution in the profile (Fig. 1) showed that values of coefficient B in Gale and Grigal's equation (1987) are 0.976 for both plants, which indicates that roots are relatively evenly distributed in the soil profile. Similar values of parameter B are given in scientific literature for tropical climate grasses, Oregon ash and some varieties of willow (Pollen-Bankhead and Simon, 2009) or black locust and Manchurian red pine (Zhang et al., 2014).

In general, roots of both species concentrate in two zones of the profile. The first one was at the ground surface, and the second one was at the depth pf $0.55-0.75 \mathrm{~m} \mathrm{bgl}$ and 
was probably associated with higher moisture content of the soil (Fig. 2). During field investigations conducted after rainfall, it was observed that water accumulated at this depth, which means that this zone is less permeable than the other ones. This phenomenon is associated with the presence of a well-compacted layer of silty sand, on whose roof there are proper conditions for water accumulation. Therefore, it can be assumed that the unusual development of the root system observed in both plant species is strongly associated with water availability.

Table 2. Distribution of roots number and root area ratio $\left(A_{1} / A\right)$ within soil profile

\begin{tabular}{c|c|c|c|c}
\hline \multirow{2}{*}{$\begin{array}{c}\text { Depth } \\
{[\mathbf{m}]}\end{array}$} & \multicolumn{2}{|c|}{ Number of roots, roots $\mathbf{~}^{-\mathbf{2}}$} & \multicolumn{2}{c}{ Ar/A, \% } \\
\cline { 2 - 5 } & Black alder & Basket willow $^{\prime}$ & Black alder & Basket willow \\
\hline 0.05 & $173 \pm 74$ & $72 \pm 28$ & $0.159 \pm 0.058$ & $0.023 \pm 0.020$ \\
0.15 & $83 \pm 36$ & $82 \pm 31$ & $0.062 \pm 0.035$ & $0.062 \pm 0.056$ \\
0.25 & $33 \pm 30$ & $42 \pm 36$ & $0.018 \pm 0.018$ & $0.042 \pm 0.037$ \\
0.35 & $30 \pm 44$ & $8 \pm 12$ & $0.015 \pm 0.025$ & $0.001 \pm 0.002$ \\
0.45 & $37 \pm 47$ & $7 \pm 8$ & $0.048 \pm 0.082$ & $0.001 \pm 0.002$ \\
0.55 & $65 \pm 84$ & $40 \pm 31$ & $0.060 \pm 0.076$ & $0.063 \pm 0.072$ \\
0.65 & $85 \pm 48$ & $72 \pm 31$ & $0.074 \pm 0.047$ & $0.041 \pm 0.030$ \\
0.75 & $43 \pm 60$ & $32 \pm 26$ & $0.029 \pm 0.044$ & $0.008 \pm 0.008$ \\
0.85 & $4.8 \pm 66$ & $0 \pm 0$ & $0.029 \pm 0.041$ & $0.000 \pm 0.000$ \\
0.95 & $0 \pm 0$ & - & $0.000 \pm 0.000$ & - \\
Mean & 60 & 39 & 0.053 & 0.027 \\
\hline
\end{tabular}

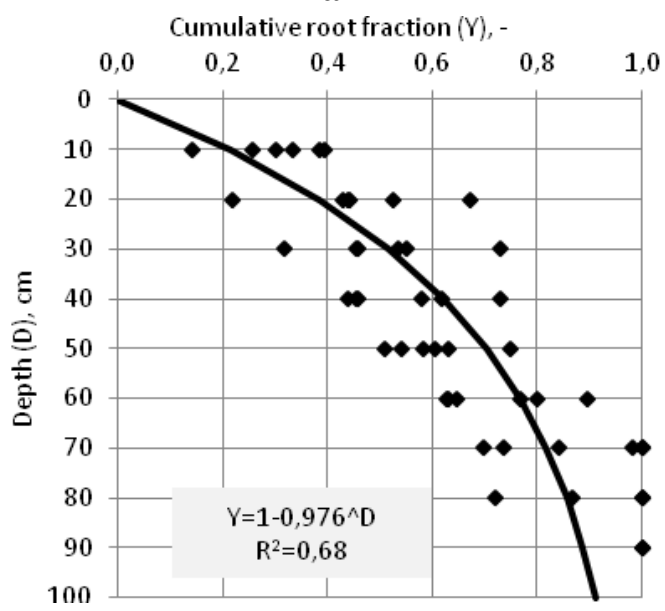

b

Cumulative root fraction $(\mathrm{Y})$, -

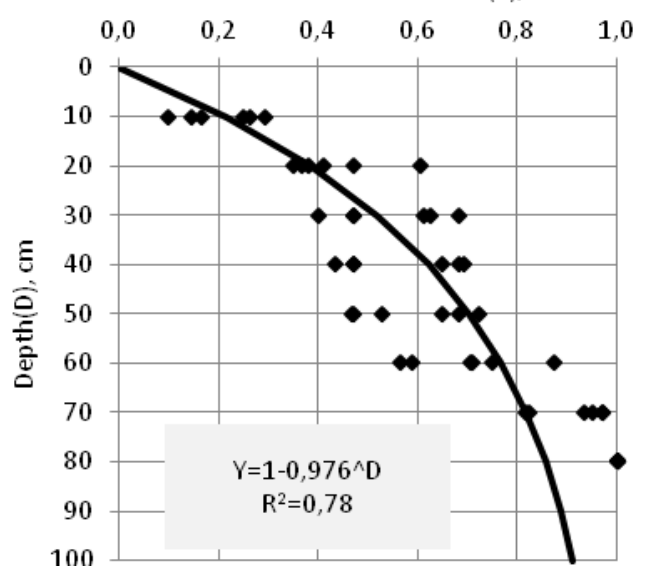

Figure 1. Cumulative numbers of black alder (a) roots and basket willow (b) roots versus soil depth

The results of measurements of the root area ratio presented in Figure 2, similar to distribution of root number, indicates high diversity in the value of this parameter. The coefficient of variation for the root area ratio in individual layers of the profile was within the range from 24 to $168 \%$ (109\%, on average), and high values of standard deviation are also indicative of the high variability of the root area ratio. The mean 
value of the black alder root area ratio in the entire profile was $0.053 \%$, and in the case of basket willow $-0.027 \%$. On the other hand, maximum values of this parameter were $0.24 \%$ in the case of alder, and $0.17 \%$ in the case of willow. Due to lack of normality of the studied property, the results of measurements were analyzed using U MannaWhitney test. This analysis showed that, at a significance level of $\alpha=0.05$, root area ratio of the studied species does not differ significantly $(\mathrm{p}=0.06)$. A similar relationship was obtained by analyzing the number of roots in the profile $(\mathrm{p}=0.12)$.

a

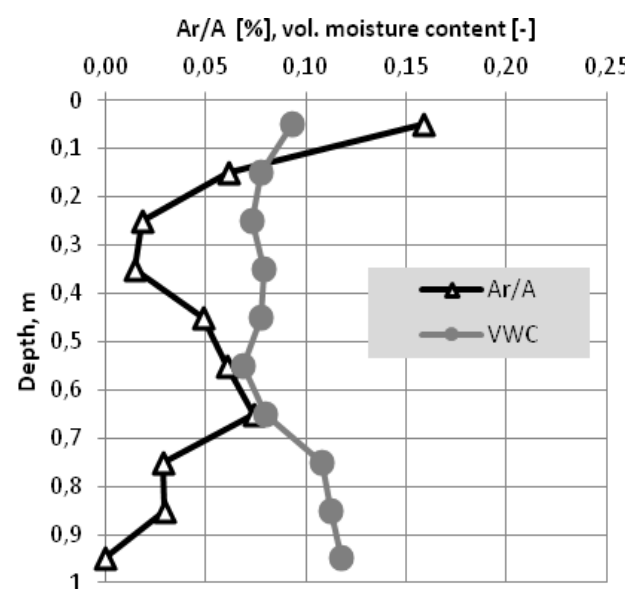

b

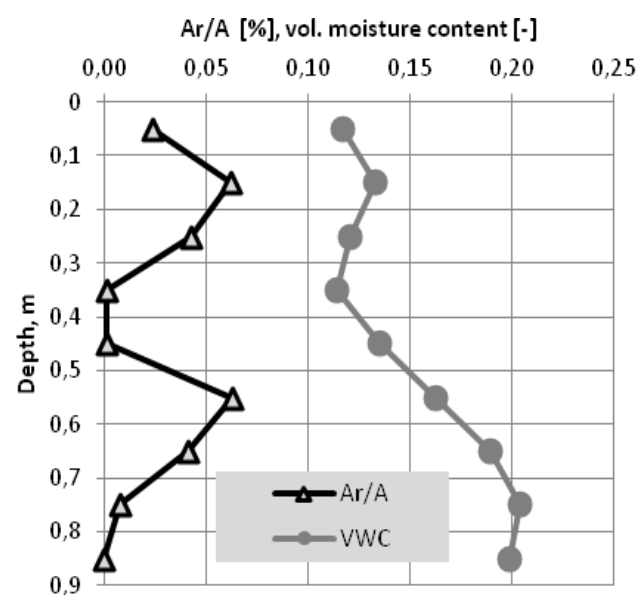

Figure 2. Root area ratio (Ar/A) and volumetric water content (VWC) of soil in a black alder plantation (a) and basket willow plantation (b)

\section{Tensile strength}

The dependence of tensile force and tensile strength on root diameter is presented in Figure 3 (for black alder) and in Figure 4 (for basket willow).

a

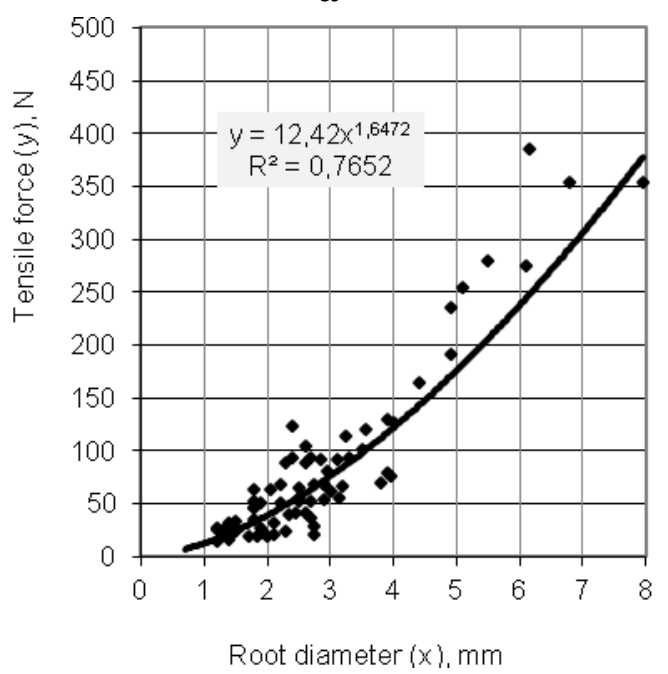

b

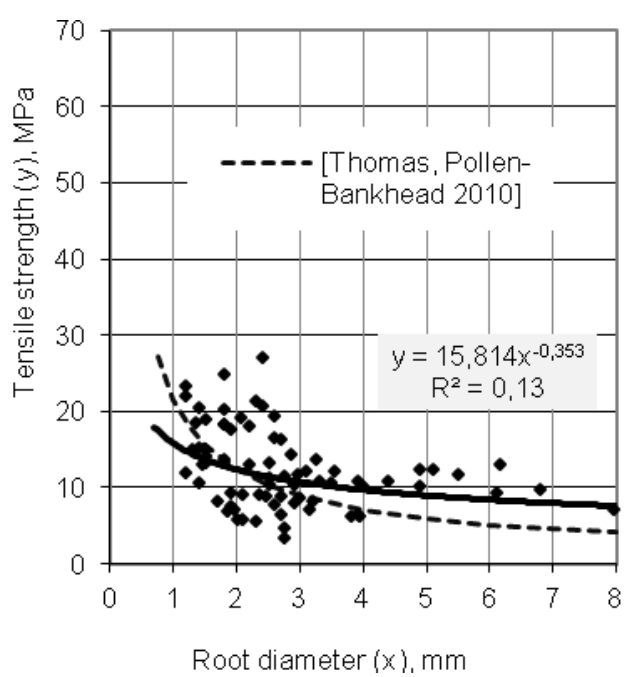

Figure 3. Tensile force (a) and tensile strength (b) versus root diameter obtained for black alder 
a

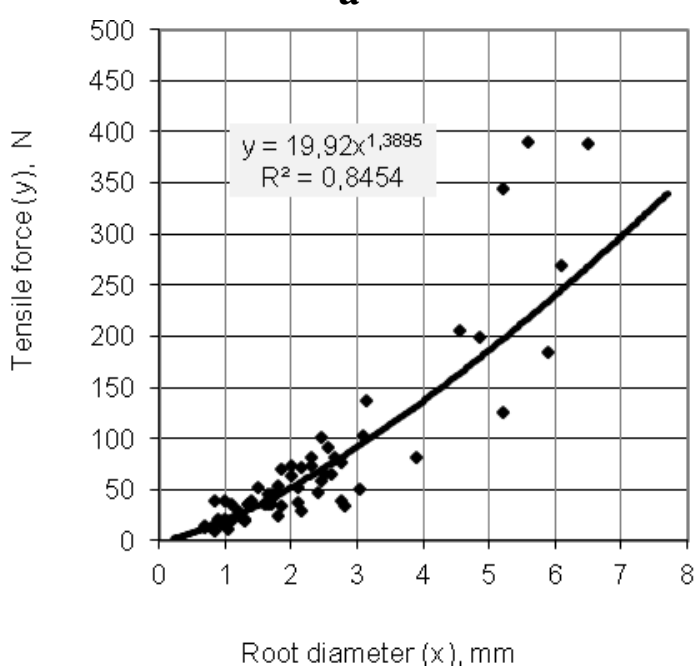

b

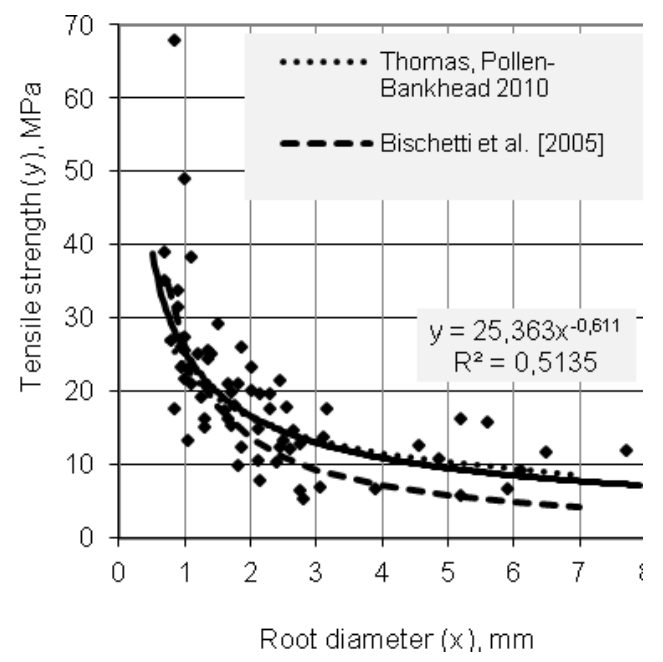

Figure 4. Tensile force $(a)$ and tensile strength $(b)$ versus root diameter obtained for basket willow

Generally, it can be said that values of tensile force were much more strongly correlated with root diameter than the dependence of tensile strength on root diameter. According to Vergani et al. (2012), the above relation results from the fact that values of tensile strength are double burdened with the root diameter measurement error. The mean value of tensile strength in the case of grey alder was $12.5 \mathrm{MPa}$ (with mean root diameter of $2.8 \mathrm{~mm}$ and standard deviation of 5.2 MPa), and in the case of basket willow - 19.5 $\mathrm{MPa}$ (with mean root diameter of $2.3 \mathrm{~mm}$ and standard deviation of $10.6 \mathrm{MPa}$ ). Statistical analysis at a significance level of 0.01 showed that tensile strength of basket willow roots is higher than that of black alder.

\section{Root cohesion}

Results of measurements of the root area ratio in the soil and root tensile strength were used to determine the magnitude of root cohesion. Calculation results presented in Figure 5 indicate that values of root cohesion change with depth analogically to the changes in the root area ratio. It is noticeable that there is a distinct difference between the values of the analyzed parameter depending on the applied calculation model. Regardless of depth and plant species, the highest values of root cohesion were obtained using the $\mathrm{Wu}$-Waldron model, and the lowest - using the RBM 2 model. To present the differences in values of root cohesion obtained by using individual calculation models, the ratio of the value of this parameter obtained from individual fiber bundle models to the value obtained using the Wu-Waldron model was calculated, using the following dependence (Eq. 13):

$$
k^{\prime \prime}=\frac{c_{r(F B M 1-F B M 3, R B M 1, R B M 2)}}{c_{r(W-W)}}
$$

It was assumed that the $\mathrm{k}$ " value was the same as the value of correction factor proposed by Preti (2006) which describes the uncertainty of determining root cohesion 
specified by the $\mathrm{Wu}$-Waldron model. The calculated values of the $\mathrm{k}$ " parameter are shown collectively in Figure 6 in the form of its dependence on the number of roots. It was generally established that, from the fiber bundle models, the highest values of the analyzed parameter were obtained using the FBM1 model, and the lowest - using the RBM2 model. It can also be observed that the more roots in the bundle, the lower the value of the analyzed parameter. This dependence is the least noticeable in the case of the RBM2 model, where values of the k" parameter obtained by this model are relatively stable and are generally within the range from 0.4 to 0.6.

a

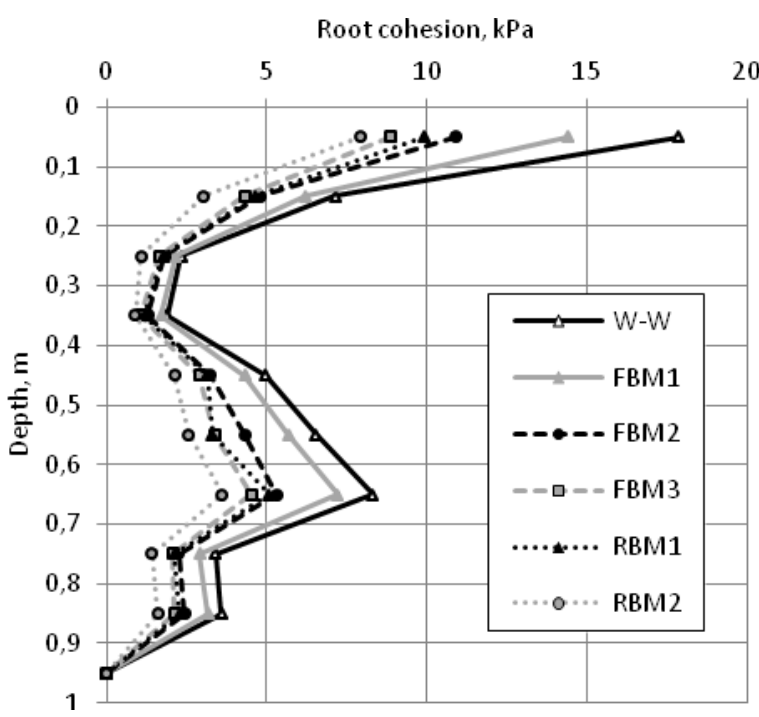

b

Root cohesion, $\mathrm{kPa}$

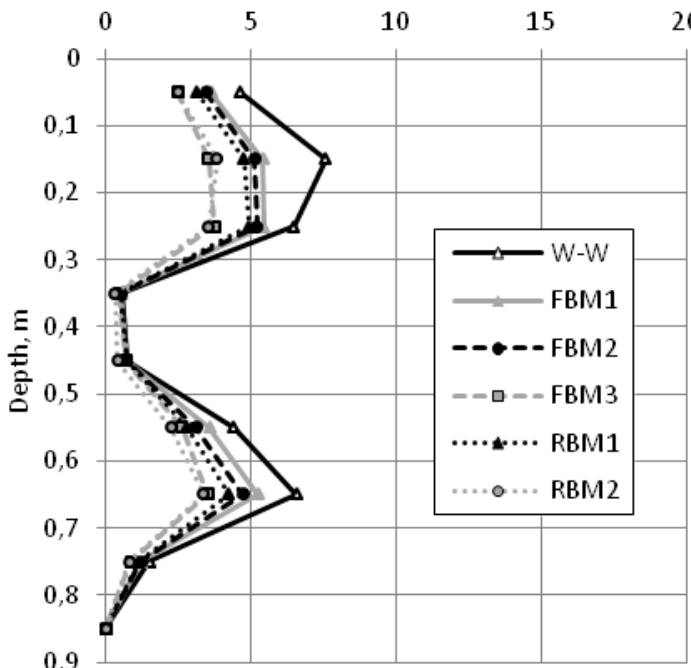

Figure 5. Mean root cohesion values determined by various models vs. depth for black alder (a) and basket willow (b) obtained using Wu-Waldron model and various fiber bundle models
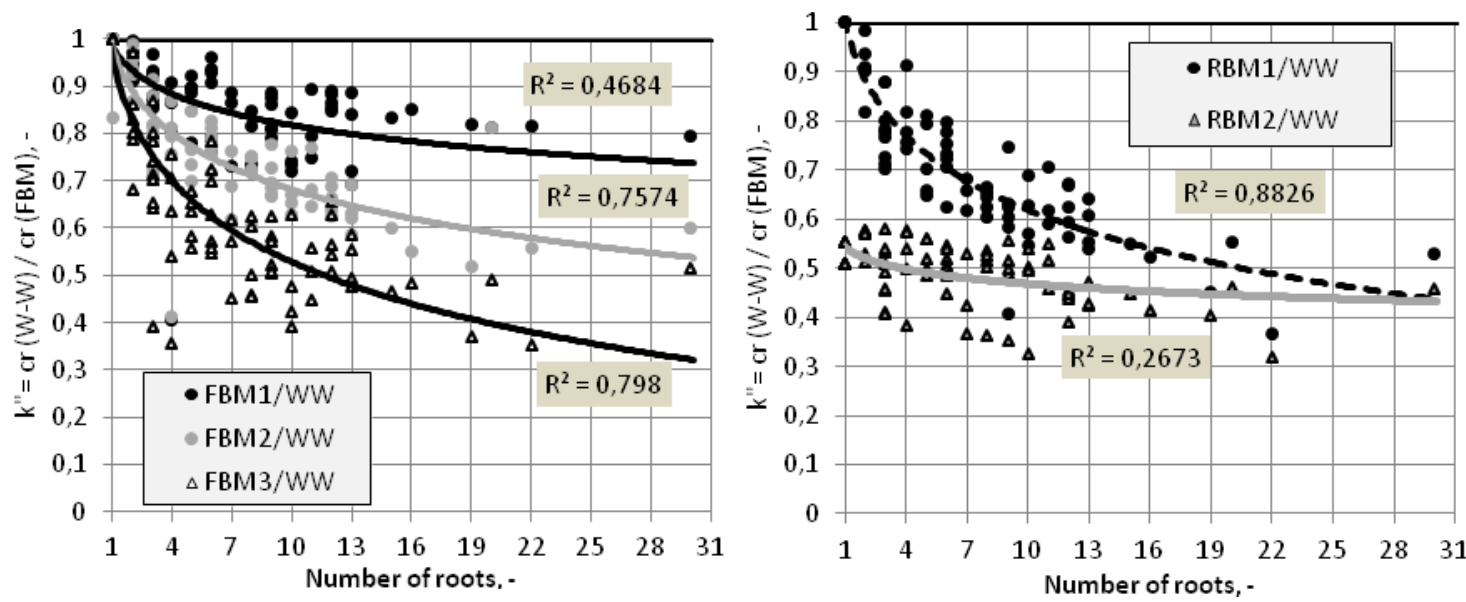

Figure 6. Values of $k^{\prime \prime}$ factor vs. number of roots

Further in the paper, for the clarity of the obtained values of root cohesion, they were averaged within profile. When comparing the studied species of trees, it was established that values of root cohesion averaged in the soil profile (Fig. 7) were relatively low, 
namely (on average, according to the $\mathrm{W}-\mathrm{W}$ model), $6.0 \mathrm{kPa}$ for black alder and $3.6 \mathrm{kPa}$ for basket willow. Values of this parameter obtained from calculations using the RBM2 model are decidedly the lowest -2.6 and $1.9 \mathrm{kPa}$ for alder and willow, respectively. The statistical analysis carried out for these data (ANOVA) showed that, in case of black alder, values of root cohesion calculated using the Wu-Waldron model differ statistically $(\mathrm{p}<0.05)$ from the results obtained using the FBM2, FBM3, RBM1 and RBM2 models, and model RBM2 provides statistically lower values of root cohesion in relation to $\mathrm{Wu}$-Waldron, FBM1 and FBM2 models. In case of basket willow, values of root cohesion obtained using FBM3, RBM1 and RBM2 models were significantly lower $(\mathrm{p}<0.05)$ than those obtained from the $\mathrm{Wu} /$ Waldron model. On the other hand, model RBM2 provides statistically lower value of root cohesion in comparison to $\mathrm{Wu}$ Waldron, FBM1 and FBM2 models. It means, that in case of the both studied species root cohesion values determined by RBM2 model are comparable to results obtained using FBM3 and RBM1 models.

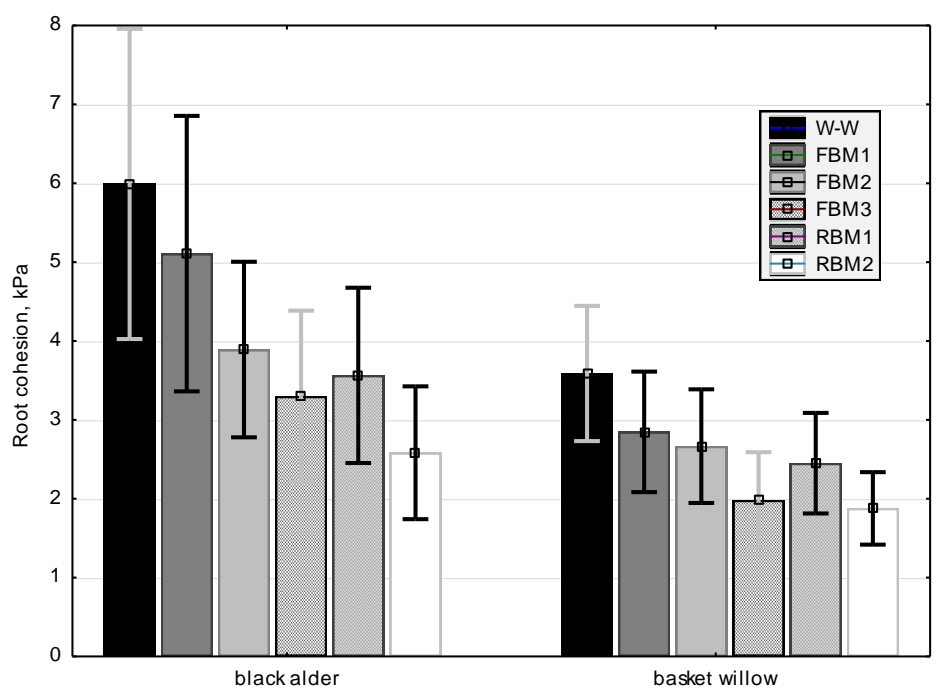

Figure 7. Site-averaged values of root cohesion

While comparing the studied plant species, it was shown (ANOVA) that values of root cohesion obtained for black alder were statistically higher $(\mathrm{p}<0.05)$ than for basket willow in case of W-W, FBM1, FBM2 and FBM3 models, whereas this difference was not observed when analyzing the results of calculations obtained from other models (RBM1 and RBM2).

\section{Discussion}

\section{Root area ratio}

Generally, it was found that mean values of the root area ratio of the studied plant species reached $0.06 \%$ and $0.03 \%$ for black alder and basket willow, respectively. The statistical analysis did not show significant differences in the value of the root area ratio of both species. As pointed out by Burylo et al. (2011), lack of statistically significant differences in tests on root systems may result from substantial heterogeneity of the results of determinations of the analyzed parameter. 
Values of the root area ratio of the studied black alder and basket willow are similar to the results obtained for root systems of black poplar and black locust from that region (Zydroń et al., 2016), while measurements of root systems of these species were taken at a slightly different distance from tree trunks $(1.0 \mathrm{~m})$. Values of the root area ratio of the studied species are also comparable to the results of measurements of a 17-year-old Chinese thuja, lower than in the case of a 17-year-old black locust (Ji et al., 2012) and higher than root systems of 9- and 10-year-old poplars (Douglas et al., 2010) or young downy oaks and black pines (maximum 0.06\%) that are presented in the paper by Burylo et al. (2011). Tests on typical European species occurring in the Alps indicate that mature trees have a much higher root area ratio, on average, by 0.07 to $0.36 \%$ (Bischetti et al., 2009), and maximum values of this parameter reach 0.9\% (Bischetti et al., 2007; 2009) or even almost 2\% (Chiaradia et al., 2012; Mao et al., 2012). So, it can be stated that the area ratio values of the studied plant species are similar to each other and are within the range provided in literature for young trees. It can be expected that the studied species will expand their roots systems.

In most tests on root systems it is characteristic that the largest number of roots, and also the highest Ar/A values, occurs in the surface part of the profile. This is associated with the reducing amount of nutrients and air in soil and an increase in its compaction (Bischetii et al., 2007). On the other hand, in the case of the studied plant species, two zones of root concentration were distinguished: near the surface $(0-0.2 \mathrm{~m} \mathrm{bgl})$ and in the lower part of the profile $(0.5-0.7 \mathrm{~m} \mathrm{bgl})$. Test results indicate that the latter zone is associated with the presence of a soil layer with higher moisture content. Tan'a et al. (2006) indicate that water availability is the most important factor determining the development of a root system. On the other hand, the observed root pattern of the studied species corresponds well to the example of root system distribution affected by site conditions (Coppin and Richards, 1990), when presence of well-compacted soil layer force roots to spread laterally.

\section{Tensile strength}

The tensile strength test results indicate a relatively good correlation between tensile force values and root diameter. When comparing the tensile strength of the studied plants to properties of other species of the same plant family, a similarity can be observed between the strength of black alder and grey alder (which was studied by Thomas and PollenBankhead (2010)). On the other hand, tensile strength of Geyer's willow (Thomas and Pollen-Bankhead, 2010) growing in North America is similar to that of the studied basket willow, whereas purple willow (Bischetti et al., 2007) has a slightly lower strength. In general, in the light of the results of tests on various plant species, obtained by various research groups and collated in the paper by Stokes et al. (2008), it can be stated that tensile strength of the studied black alder is within the lower range of strength values for deciduous trees, whereas the mean strength value of basket willow is basically typical for shrubs. It should be highlighted, however, that test results presented in the paper by Stokes et al. (2008) were obtained using various methods differing in the way of preparing samples for tests and also in the tensing procedure itself.

\section{Root cohesion}

The obtained calculation results indicate a relatively low effect of root systems of the studied plant species on soil stabilization in relation to root systems of young black 
locust trees and Chinese thuja shrub (Ji et al., 2012; Zydroń et al., 2016), Japanese cedar (Genet et al., 2008) or mature tree species occurring in European forests (Bischetii et al., 2009; Vergani et al., 2014). The low effect of the black willow root system on root cohesion was also indicated by Simon and Collins (2002) who obtained the mean value of root cohesion of $2 \mathrm{kPa}$. However, it should be stressed that the obtained test results are similar to the values of root cohesion of black poplar (Zydron et al., 2016), of vetiver grass (Mickovski et al., 2009), or higher than some shrub species (Burylo et al., 2011; Adhikari et al., 2013).

When comparing the results of calculations of root cohesion, obtained using the $\mathrm{Wu}$ Waldron model and fiber bundle model, it was found that they were clearly different, which is in accordance with existing knowledge (Pollen and Simon, 2005; Bischetii et al., 2009; Mao et al., 2012). Values of root cohesion obtained using fiber bundle models are, on average, $12-51 \%$ lower than those obtained from calculations using the $\mathrm{Wu}$ Waldron model, which means that, in extreme cases, the Wu-Waldron model yields over twice overestimated values of root cohesion.

From the fiber bundle models, the highest values of the analyzed parameter were obtained using the FBM1 model, which assumes that tensile strength distribution is proportional to the root cross-section area, which means that each root is under the same stresses. This assumption is the reason why, when under tension, coarse roots are damaged first, which is contradictory to the results of the paper by Cohen et al. (2011), which indicate that fine roots are usually damaged first. The same relationship was obtained for the other models. Similar relationships concerning the differences in results of calculations of root cohesion and the order of root breaking in the bundle, obtained using FBM1, FBM2 and FBM3 models, are described in papers by Mao et al. (2012) and Ji et al. (2012).

Calculations obtained using deformation models (RBM1 and RBM2) yielded interesting results. These models have the same assumption regarding the way of tensile force distribution as in the FBM1 model, but these models assume that roots have different lengths (roots with small diameter are shorter than coarse roots). The last assumption causes that fine roots, despite their substantial elasticity, are the first to be damaged (broken, pulled out from soil). Values of root cohesion obtained using deformation models RBM1 and RBM2 were, on average, 25 and 51\% lower than obtained from the Wu-Waldron model. Values of root cohesion generated by RBM1 model were lower than values of the analyzed parameter obtained using FBM1 and FBM2 models, which is contrary to the results of Ji et al. (2012). In turn, RBM 2 model generated the lowest values of root cohesion among analyzed models. This model takes into account the diversity in root tensile strength, and thereby the value of tensile force transmitted by individual roots is multiplied by the factor of probability of root damage. Contrary to the other models, the ratio between root cohesion determined from this model and the Wu-Waldron model did not depend much on the number of roots (cf. Fig. 7) and amounted on average 0.49 , which is close to the value of correction factor k" proposed in the paper by Bischetti et al. (2009) (k"=0.5). Therefore, it appears that $\mathrm{k} "=0.5$ may be a parameter that, from the practical point of view, can be used to calculate root cohesion using the classic $\mathrm{Wu} / \mathrm{Waldron}$ model, thus gaining time and simplification of calculations in relation to calculation procedures used in fiber bundle models.

The authors of the RBM2 model (Schwarz et al., 2013), draw attention to the fact that the results of calculations of the force transmitted by roots are significantly influenced by variability of their strength-related properties, which is expressed by the 
value of the parameter $\omega$. High values of this parameter are indicative of substantial homogeneity of the studied plant material, whereas results of analyses carried out by the authors of this model indicate that this parameter usually amounts to approximately 2 , which is similar to the values obtained in the tests herein (for black alder $\omega=2.6$, and for basket willow $\omega=3.0$ ). Schwarz et al. (2013) also show that results of calculations obtained using the RBM2 model show a relatively good concurrence with results of direct tests. However, as the authors of this model highlight themselves, it requires further work on validation of the values of Weibull function parameters for different combination of factors taking into account the type of test method, method of data elaboration and the number of repetitions.

\section{Conclusion}

Based on the obtained results of research on black alder and basket willow root systems from a seven-year plantation, it can be stated that:

1. The studied species are characterized by substantial variability in the root system area ratio, which is typical for this type of material. Moreover, field measurements showed that (in the existing habitat conditions) both plants developed a complex root system in which roots concentrated in the surface part of the profile and in the deeper zone where there are appropriate conditions for drawing water from soil.

2. Tensile strength tests showed a strong connection between tensile force and root diameter. Tensile strength of black alder roots was, in statistical terms, considerably lower than that of basket willow roots.

3. Calculations of root cohesion of both of the studied plant species indicate that they had relatively low values of this parameter, which was associated with their young age.

4. It was shown that evaluation of the effect of the root system on root cohesion is significantly associated with the applied calculation model and calculation assumptions associated with it. It was shown that fiber bundle models yield lower values of root cohesion than the classic $\mathrm{Wu}$-Waldron model. On the other hand, among the fiber bundle models, the lowest values of the investigated parameter were obtained using the Root Bundle Model proposed by Schwarz et al. (2013) that takes into account the function of probability distribution of root tensile strength. Statistical analysis revealed that root cohesion results obtained this model, results from Root Bundle Model described in paper as RBM1 and FBM3 can be considered as comparable.

5. Application of the deformation model which takes into account the Weibull's function of probability distribution leads to obtainment of root cohesion values which are approximately 50\% lower than Wu-Waldron model. Therefore, application of the correction factor (proposed by Preti, 2006), at a value of 0.5 , in the $\mathrm{Wu}$-Waldron model allows for a relatively easy way to determine realistic values of root cohesion which appear safe from the point of view of engineering applications.

6. Considering application of the obtained test results into practice it seems important to predict development of root system. So, future tests should be concentrated on studies of the root systems growth and its impact on root cohesion and slope stability. 
Acknowledgements. The paper was prepared as a part of the statutory research: DS-3322/KIWiG/2017.

\section{REFERENCES}

[1] Adhikiri, A. R., Gautam, M. R., Yu, Z., Imada, S., Acharya, K. (2013): Estimation of root cohesion for desert species in the Lower Colorado riparian ecosystem and its potential for streambank stabilization. - Ecological Engineering 51: 33-44.

[2] Bischetti, G. B., Chiaradia, E. A., Simonato, T., Speziali, B., Vitali, B., Vullo, P., Zocco, A. (2007): Root strength and root area ratio of forest species in Lombardy (Northern Italy). - Plant and Soil 278: 11-22.

[3] Bischetti, G. B., Chiaradia, E. A., Epis, T., Morlotti, E. (2009): Root cohesion of forest species in the Italian Alps. - Plant and Soil 324: 71-89.

[4] Böhm, W. (1979): Methods of Studying Root Systems. - Springer-Verlag Berlin, Heidelberg, New York.

[5] Burylo, M., Hudek, C., Rey, F. (2011): Soil reinforcement by the roots of six dominant species on eroded mountainous marly slopes (Southern Alps, France). - Catena 84: 7078.

[6] Chiaradia, E A, Bischetti, G B, Vergani, C (2012): Incorporating the effect of root systems of forest species into spatially distributed models of shallow landslides. International Journal of Forest, Soil and Erosion 2(3): 107-118.

[7] Cohen, D., Schwarz, M., Or, D. (2011): An analytical fiber bundle model for pullout mechanics of root bundles. - Journal Of Geophysical Research 116: F03010. doi:10.1029/2010JF001886.

[8] Comino, E., Marengo, P. (2010): Root reinforcement effect of different grass species: A comparison between experimental and models results. - Soil \& Tillage Research 110: 6068.

[9] Coppin, N. J., Richards, I. G.(1990): Use of Vegetation in Civil Engineering. Butterworth, London.

[10] Docker, B. B., Hubble, T. V. T. (2008): Quantifying root-reinforcement of river bank soils by four Australian tree species. - Geomorphology 100: 401-418.

[11] Douglas, G. B., McIvor, I. R., Potter, J. F., Foote, L. G. (2010): Root distribution of poplar at varying densities on pastoral hill country. - Plant and Soil 333: 147-161.

[12] Fijałkowska, D., Styszko, L. (2011): Ciepło spalania biomasy wierzbowej. - Rocznik Ochrona Środowiska (Annual Set of Environment Protection) 13: 875-889.

[13] Gale, M. R., Grigal, D. F. (1987): Vertical root distributions of northern tree species in relation to successional status. - Canadian Journal of Forest Research 17: 829-834.

[14] Genet, M., Kokutse, N., Stokes, A., Forcaud, T., Cai, X., Ji, J., Mickovski, S. (2008): Root reinforcement in plantations of Cryptomeria japonica D. Don: effect of tree age and stand structure on slope stability. - Forest Ecology and Management 256: 1517-1526.

[15] Jaworski, A. (1995): Charakterystyka hodowlana drzew leśnych. - Gutenberg, Kraków.

[16] Ji, J., Kokutse, N., Genet, M., Fourcaud, T., Zhang, Z. (2012): Effect of spatial variation of tree root characteristics on slope stability. A case study on Black Locust (Robiniapseudoacacia) and Arborvitae (Platycladusorientalis) stands on the Loess Plateau, China. - Catena 92: 139-154.

[17] Mao, Z., Saint-Andre, L., Genet, M., Mine, F-X., Jourdan, Ch., Rey, H., Courbaud, B., Stokes, A. (2012): Engineering ecological protection against landslides in diverse mountain forests: Chosing cohesion models. - Ecological Engineering 45: 55-69.

[18] Mattia, C., Bischetti, G. B., Gentile, F. (2005): Biotechnical characteristics of root systems of typical Mediterranean species. - Plant and Soil 278: 23-32.

[19] Mickovski, S. B., van Beek, L. P. H. (2009): Root morphology and effects on soil reinforcement and slope stability of young vetiver (Vetiveria zizanioides) plants grown in semi-arid climate. - Plant and Soil 324: 43-56. 
[20] Pollen, N., Simon, A. (2005): Estimating the mechanical effects of riparian vegetation on stream bank stability using a fiber bundle model. - Water Resources Research 41: W07025. doi:10.1029/2004WR003801.

[21] Pollen-Bankhead, N., Simon, A. (2009): Enhanced application of root-reinforcement algorithms for bank-stability modeling. - Earth Surf. Process. Landforms 34: 471-480.

[22] Preti, F. (2006): On root reinforcement modeling. - European Geosciences Union. Geophysical Research Abstracts 8: 04555.

[23] Rai, R., Shrivastva, B. K. (2012): Large in situ shear test box for mine waste dump. - J. Inst. Eng. India Ser. D 93(1): 19-22.

[24] Schmidt, K. M., Roering, J. J., Stock, J. D., Dietrich, W. E., Montgomery, D. R., Schaub, T. (2001): The variability of root cohesion as an influence on shallow landslide susceptibility in the Oregon Coast Range. - Canad. Geotech. J. 38: 995-1024.

[25] Schwarz, M., Thormann, J-J., Zürcher, K., Feller, K. (2012): Quantifying root reinforcement in protection forests: implications for slope stability and forest management. - 12th Congress INTERPRAEVENT 2012, Grenoble 791-802.

[26] Schwarz, M., Giadrossich, F., Cohen, D. (2013): Modeling root reinforcement using a root-failure Weibull survival function. - Hydrology and Earth System Sciences 17: 43674377.

[27] Simon, A., Collins, A. J. C. (2002): Quantifying the mechanical and hydrologic effects of riparian vegetation on streambank stability. - Earth Surface Processes and Landforms 27: 527-546.

[28] Sonnenberg, R., Bransby, M. F., Hallet, P. D., Bengough, A. G., Mickovski, S. B., Davies, M. C. R. (2010): Centrifuge modelling of soil slopes reinforced with vegetation. - Canadian Geotechnical Journal 47: 1415-1430.

[29] Stachowski, P. (2006): Kształtowanie środowiska rolniczego na terenach pogórniczych Kopalni Węgla Brunatnego „Konin”. - Rocznik Ochrona Środowiska (Annual Set of Environment Protection) 8: 279-297.

[30] Stokes, A., Norris, E., van Beek, L. P. H., Bogaard, T., Cammeraat, E., Mickovski S. B., Jenner, A., Di Iorio A., Fourcaud, T. (2008): How Vegetation Reinforces Soil on Slopes. - In: Norris, J. E. et al. (eds.) Slope Stability and Erosion Control: Ecotechnological Solutions. Springer, Dordrecht.

[31] Tan, Y., Wang, C. R., Liang, Z. S., Du, F., (2006): Measures for forest and grass vegetation construction in semi-arid areas on the Loess Plateau. - Acta Prataculturae Sinica 15(4): 4-11.

[32] Thomas, R. E., Pollen-Bankhead, N. (2010): Modeling root-reinforcement with a fiberbundle model and Monte Carlo simulation. - Ecological Engineering 36: 47-61.

[33] Vergani C., Chiaradia, E. A., Bischetti, G. B. (2012): Variability in the tensile resistance of roots in Alpine forest tree species. - Ecological Engineering 46: 43-56.

[34] Vergani, C., Chiaradia, E. A., Bassanelli, C., Bischetti, G. B. (2014): Root strength and density decay after felling in a Silver Fir-Norway Spruce stand in the Italian Alps. - Plant and Soil 377: 63-81.

[35] Waldron, L. J. (1977): The shear resistance of root-permeated homogeneous and stratified soil. - Journal of the Soil Science Society of America 41: 843-849.

[36] Wu, T. H., McKinnell III, W. P., Swanston, D. N. (1979): Strength of tree roots and landslides on Prince of Wales Island, Alaska. - Canadian Geotechnical Journal 16: 19-33.

[37] Zhang, C., Chen, L-H., Jiang, J. (2014): Vertical root distribution and root cohesion of typical tree species on the Loess Plateau, China. - Journal of Arid Land 6(5): 601-611. doi: 10.1007/s40333-014-0004-x.

[38] Zydroń, T., Bienias, B., Gruchot, A. T. (2016): Wpływ systemu korzeniowego topoli czar-nej i robinii akacjowej na wytrzymałość na ścinanie gruntów. - Rocznik Ochrona Środowiska (Annual Set of Environment Protection) 18: 772-799. 